\title{
Simulasi Monitoring Pergeseran Tanah Menggunakan Sensor LVDT (Linear Variable Differential Transformer)
}

\author{
Wilson Jefriyanto*1, Bergita Gela M. Saka², Jumiarti Andi Lolo ${ }^{3}$, Irsan Rahman ${ }^{4}$ \\ $* 1,2,3$ Universitas Kristen Indonesia Toraja \\ ${ }^{4}$ Universitas Muslim Maros,
}

e-mail: *1 wilsonjefriyanto@gmail.com, ${ }^{2}$ bergita@ukitoraja.ac.id, ${ }^{3}$ mia.andilolo@gmail.com,

irsan@umma.ac.id,

\begin{abstract}
Abstrak
Pergeseran tanah merupakan salah satu faktor terjadinya tanah longsor (landslide). Untuk itu, diperlukan suatu prototype alat yang dapat membantu memberikan informasi dini dan peringatan akan terjadinya longsor. Telah dilakukan penelitian tentang simulasi pergeseran tanah dengan menggunakan sensor LVDT (Linear Variable Differential Transformer). Sensor LVDT dihubungkan dengan Arduino uno yang kemudian ditampilkan pada LCD dan juga monitoring pada komputer. Pengamatan pergeseran tanah dilakukan selama 5 jam dengan melakukan variasi terhadap sudut kemiringan tanah. Tujuan dari penelitian ini yaitu untuk menguji kerja dari sensor LVDT yang merupakan hasil dari penelitian sebelumnya. Dari hasil pengamatan, terlihat bahwa sensor LVDT ini mampu membaca pergeseran tanah dengan ketelitian $0.01 \mathrm{~mm}$ dengan jangkauan pergeseran hingga $14 \mathrm{~cm}$. Hal ini menunjukkan sensor LVDT dapat dijadikan alat monitoring untuk pergeseran tanah yang kecil. Penelitian selanjutnya akan dikembangkan sensor LVDT dengan jangkauan pengukuran yang besar.
\end{abstract}

Kata kunci: Landslide, LVDT, Pergeseran Tanah, Sensor

\section{PENDAHULUAN}

Perkembangan teknologi sensor saat ini tidak hanya pada bidang industri, tetapi juga merambah pada bidang lain, seperti bidang medis, bangunan, mitigasi bencana otomotif, komunikasi, teknologi informasi, dan bidang lainya (Jefriyanto, 2017). Dalam bidang mitigasi bencana, salah satu sensor yang digunakan yaitu sensor untuk mengamati pergerakan tanah untuk mangantisipasi terjadinya tanah longsor yang rawan terjadi di Indonesia, seperti di wilayah Tana Toraja dan Toraja Utara yang merupakan daerah dataran tinggi dan sering terjadi longsor (Priyanto, 2015). Perumahan dan pemukiman warga semakin meningkat setiap tahunnya, dimana pohon-pohon yang juga berfungsi menahan longsoran banyak yang sudah ditebang sehingga titik-titik longsor semakin banyak. Jadi diperlukan suatu prototype alat yang dapat membantu memberikan informasi dini dan peringatan akan terjadinya longsor.

Pengamatan pergerakan tanah telah dikembangkan dengan beberapa alat instumen antara lain extensometer elektris, inclinometer dan FBG stainmeter (Kanchi dan Gosala, 2010; Vudhivanich dan Sriwongsa, 2011; Othman, 2008). Selain ketiga sistem instrumentasi tersebut, salah satu sistem monitoring yang telah berhasil dibuat dengan harga harga komponen yang lebih terjangkau yaitu sistem pergeseran tanah menggunakan sensor LVDT (Linear Variabel Differential Transformer) berbasis mikrokontroler yang merupakan hasil penelitian kami sebelumnya (Jefriyanto, 2018). Namun untuk memaksimalkan hasil pengukuran dari sensor, diperlukan pengujian sebelum diterapkan di lapangan. Untuk itu perlunya prototype simulasi sensor LVDT yang akan memonitoring pergeseran tanah sebagai media uji coba Sensor LVDT.

Penelitian sebelumnya telah berhasil dibuat sensor LVDT yang dilakukan secara manual dengan menggunakan penggulung kawat kemudian dihubungkan dengan rangkaian pengarah arus dan mikrokontroler serta LCD untuk tampilan pengukuran (Jefriyanto, 2019). Kinerja LVDT ditentukan oleh geometri tranduser, 
variasi eksitasi, arus dan frekuensi untuk menentukan kinerja yang diusulkan (Kanchi dan Gosala, 2010). Hasil pembuatan sensor LVDT yang telah buat dapat dilihat pada gambar berikut.

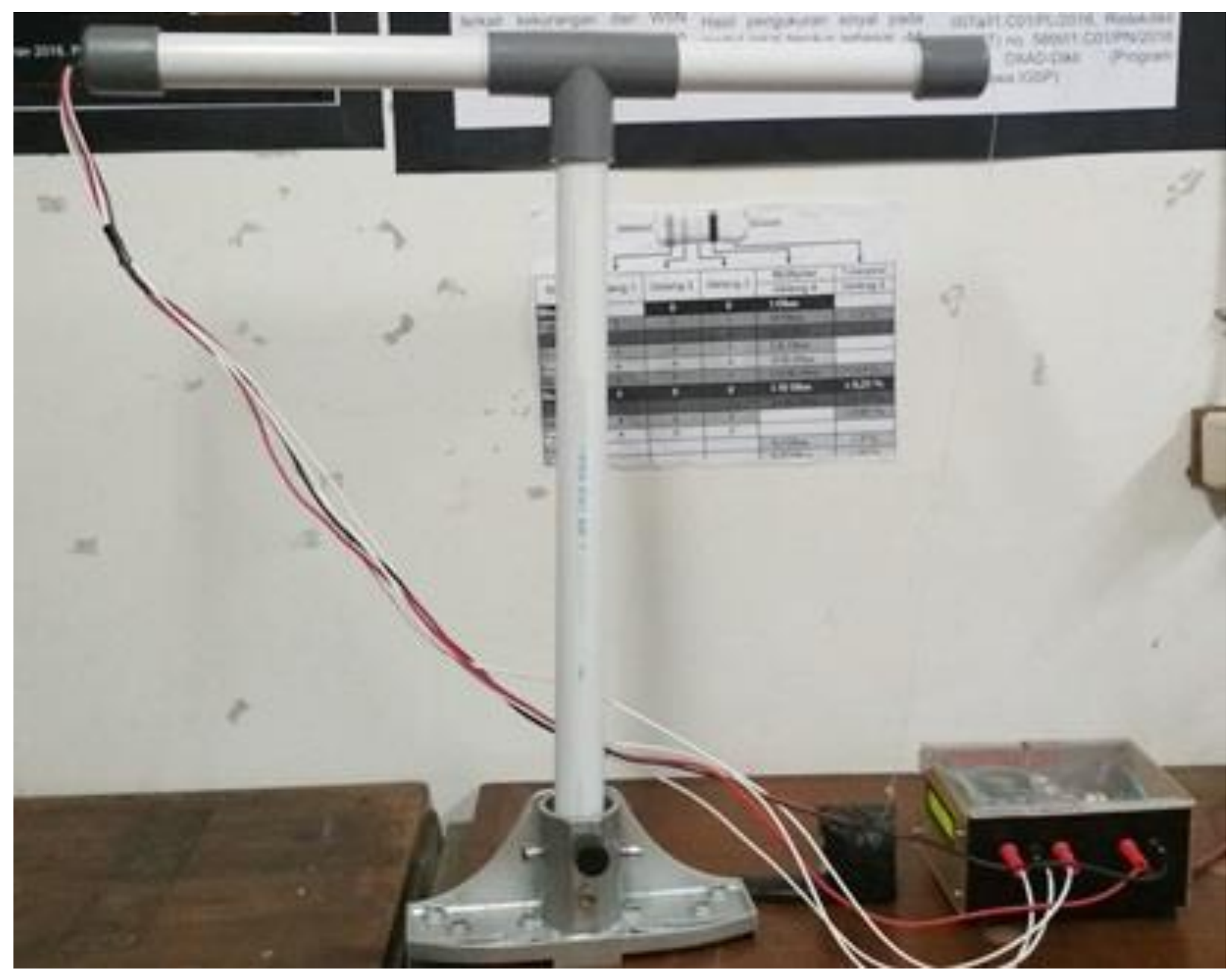

Gambar 1. Sensor LVDT

Pergeseran tanah (land displacement) merupakan peristiwa alam dimana volume tanah atau batuan dalam satu area tertentu mengalami perubahan posisi dari keadaan awalnya. Pemuaian massa tanah akibat kadar air yang berlebih, merupakan salah satu daktor pergerakan tersebut. Selain itu, akibat juga diakibatkan dari perbedaan struktur dan jenis batuan penyusun tanah sehingga dengan kondisi tanah atau lereng yang curam dapat memicu terjadinya pergerakan tanah yang cenderung mengarah ke bagian bawah akibat pengaruh gravitasi.

Pengamatan longsor yang telah dilakukan oleh beberapa ahli diperoleh kesimpulan bahwa untuk daerah dengan kondisi kemiringan lereng $>45^{\circ}$, apabila dalam area dengan kondisi tanah yang labil telah terjadi pergeseran tanah sebesar $\pm 5 \mathrm{~cm}$, maka wilayah tersebut berpotensi mengalami longsor (Karnawati, 2012).

Peristiwa tanah longsor merupakan pergerakan reruntuhan batu atau kotoran bawah pada sebuah kemiringan yang berakibat dari kegagalan konstituen pada lereng gunung yang didorong oleh gaya gravitasi (Kapoor dkk., 2016). Sealin itu, tanah longsor juga dipengaruhi oleh kondisi geologis dan geografis yang kompleks dan perubahan kondisi iklim dalam waktu tertentu (Federico dkk., 2004).

Karena banyaknya parameter yang harus diperhatikan dalam menganalisis terjadinya longsor maka dibuatlah simulasi untuk mengoptimalkan pengamatan pada saat di lapangan. Simulasi ini ada yang berbentuk komputasi (Nuhn, E. dkk, 2012) dan juga dalam bentuk perangkat eksperimen seperti pada gambar 2. Pada 
https://jurnal.unsulbar.ac.id/index.php/saintifik

gambar 2, perangkat eksperimen ini dilakukan pemantauan dan pengembangan lahan longsor yang terhubung dengan sistem wireless yang dilakukan oleh oleh Centre for Spatial Data Analysis and Sustainable Development Applications Universitas Tongji (Scaioni dkk., 2012).

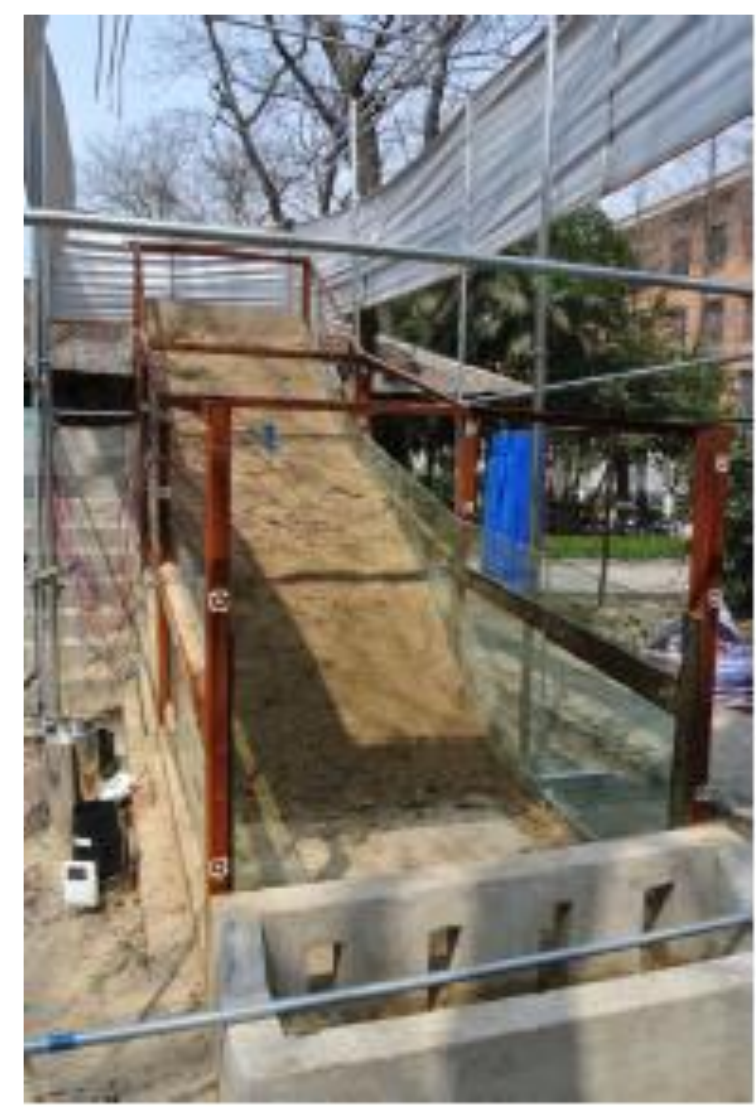

Gambar 2. Platform simulasi landslide (Scaioni dkk., 2012).

\section{METODE PENELITIAN}

Metode penelitian ini menggunakan metode eksperimen. Diagram alir tahapan dalam penelitian ini dapa dilihat pada skema gambar 3 berikut ini.

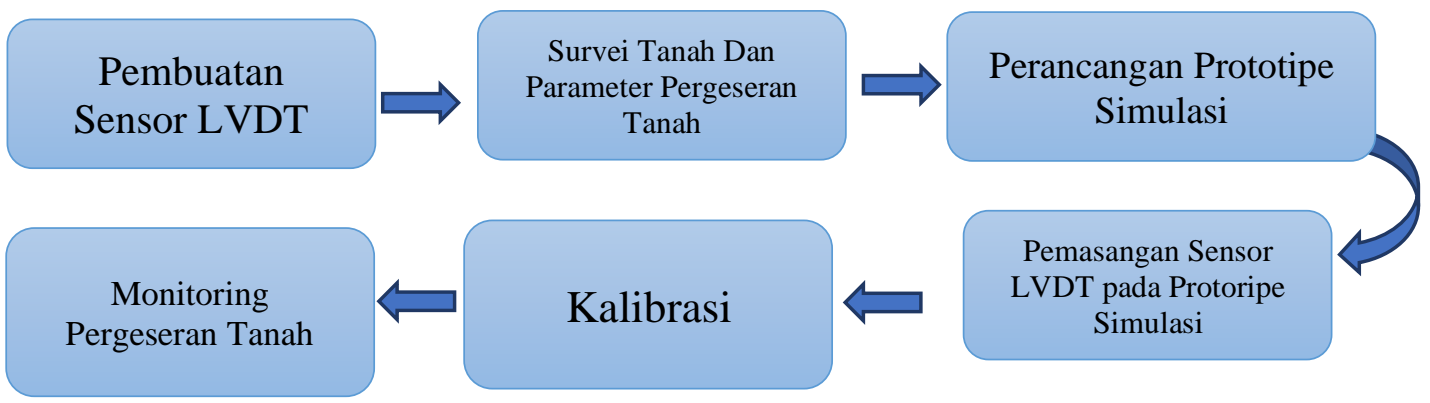

Gambar 3 Diagram alir pengembangan sensor LVDT

Proses awal diawali dengan pembuatan sensor LVDT dengan menggunakan alat penggulung kawat yang memiliki counter lilitan sehingga memudahkan dalam perhitungan jumlah lilitan. Sensor ini terdiri dari lilitan primer dan sekunder. Pada lilitan primer dihubungkan dengan sumber arus AC, dengan sinyal sinusoidal 
yang akan membuat lilitan - lilitan sekunder terbangkit dengan tegangan induksi (Othman, 2008). Rancangan sensor LVDT yang telah dibuat pada penelitian dapat dilihat pada gambar 4. Sebelum prototype dibuat, maka dilakukan survei jenis-jenis tanah yang ada di daerah rawan longsor yang nantinya digunakan untuk bahan simulasi.

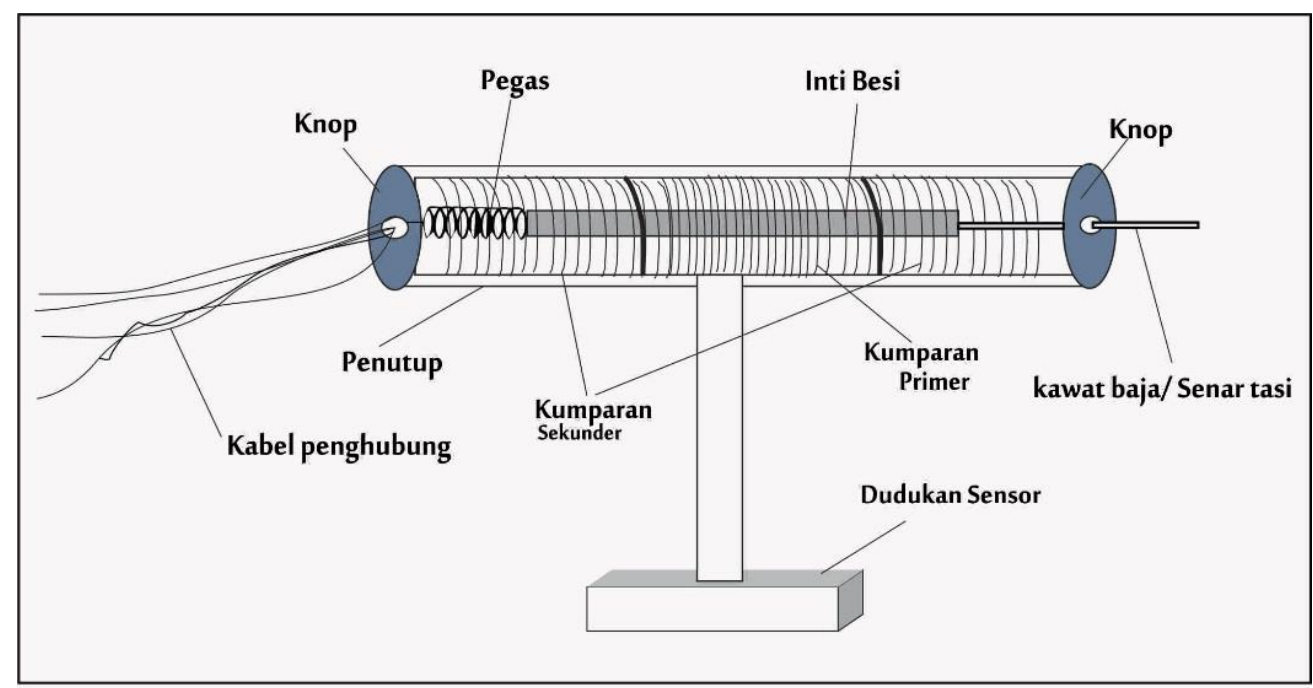

Gambar 4. Desain sensor LVDT

Pergeseran tanah ini diamati secara langsung di lokasi rawan longsor dan juga dalam bentuk simulasi. Namun agar hasil pengukuran pada sensor LVDT lebih baik, maka dilakukan simulasi dalam skala laboratorium. Untuk pengukuran di lapangan akan dilakukan pada tahap penelitian selanjutnya. Pada tahap simulasi ini, dilakukan perancangan alat simulasi, selanjutnya melakukan survei tanah dana parameter lain di lokasi rawan longsor. Setelah itu prototype simulasi dirancang dengan menggunakan beberapa sensor untuk mengamati parameter lain yang mempengaruhi pergeseran tanah. Agar hasil data monitoring valid, maka seluruh alat dikalibrasi sebelum pengambilan data. Adapun gambar rancangan prototype simulasi yang akan dibuat dapat dilihat pada gambar 5 .

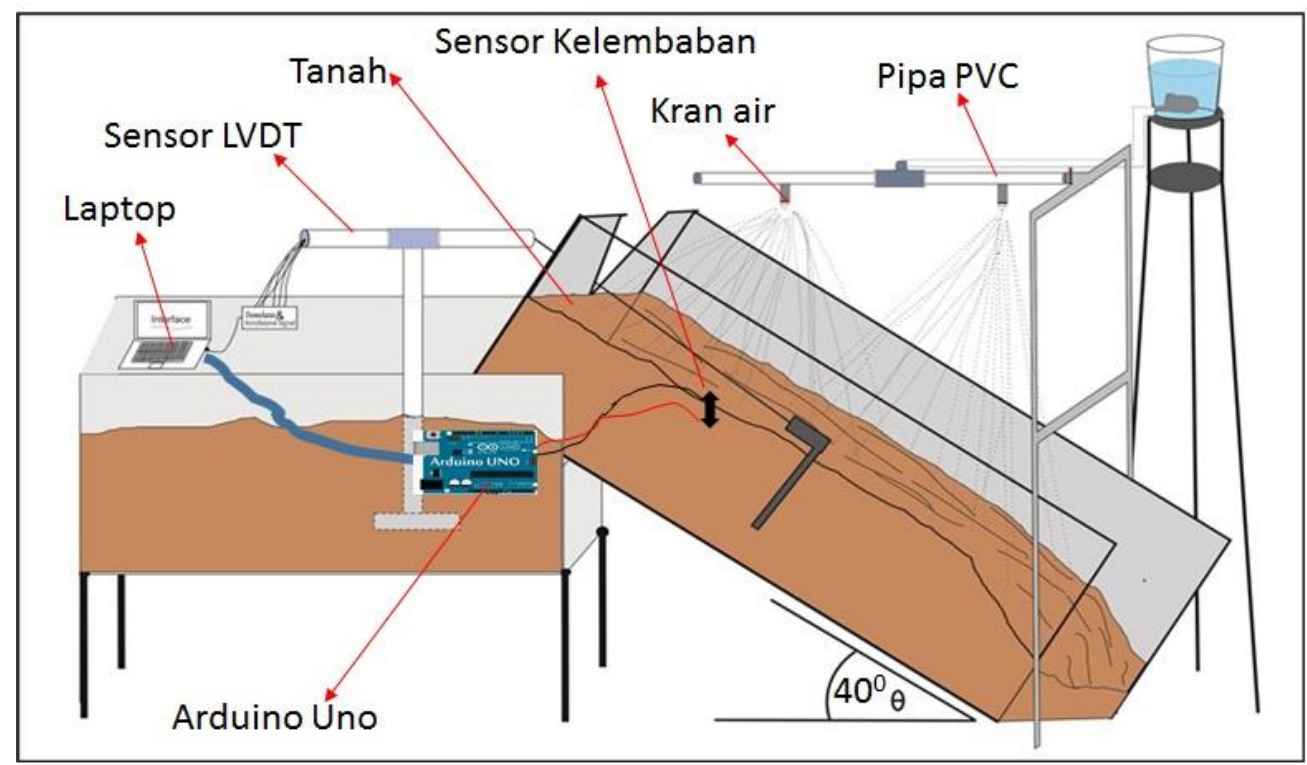

Gambar 5. Skematik prototipe Sistem pengukuran pergeseran tanah 


\section{https://jurnal.unsulbar.ac.id/index.php/saintifik}

\section{HASIL DAN PEMBAHASAN}

Pada simulasi ini tanah dimasukkan ke dalam wadah yang berukuran $100 \mathrm{~cm}$ x $30 \mathrm{~cm}$ x $30 \mathrm{~cm}$. Wadah ini kemudian dimiringkan sampai membentuk sudut yang diinginkan. Untuk membuat gerakan tanah, maka tanah tersebut disirami air menggunakan pipa yang didesain khusus agar air bisa merata menyebar ke seluruh wadah. Agar air yang keluar konstan, maka pada sistem ini digunakan pompa air dengan debit air 3,76 cc/detik. Adapun perangkat eksperimen yang telah dibuat untuk simulasi ini dapat dilihat pada gambar 3 .

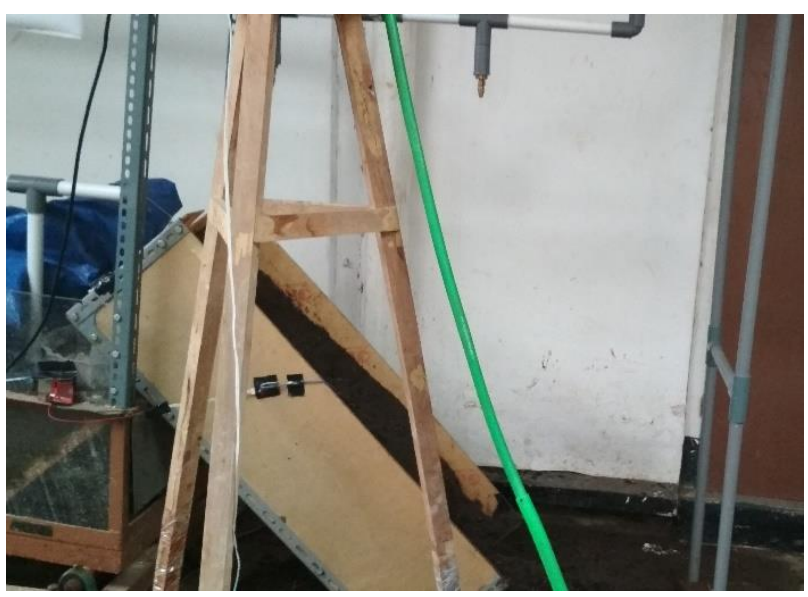

(a)

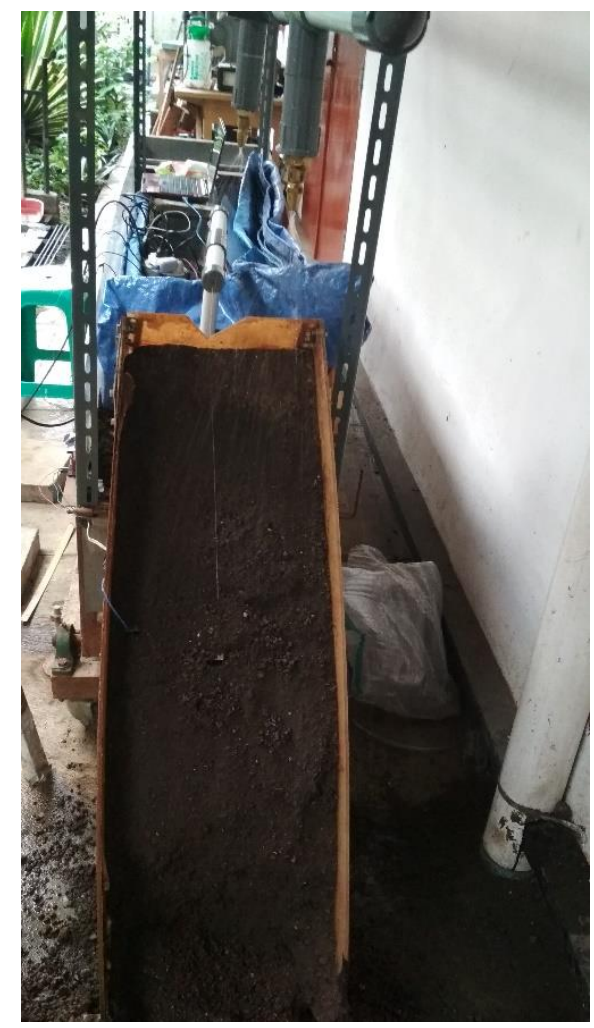

(b)

Gambar 6. Perangkat eksperimen landslide(a) tampak dari samping (b) tampak dari depan

Sudut kemiringan wadah yang digunakan yaitu sudut $40^{\circ}, 45^{\circ}$, dan $50^{\circ}$ seperti pada gambar IV.11.Lamanya waktu penyiraman yaitu 18.000 sekon atau sekitar 5 jam. Pada saat menit ke 30 mulai terjadi 
retakan pada tanah yang membuat tanah bergeser. Data pergeseran ini terbaca oleh sensor yang ditampilkan melalui LCD, dan juga tersimpan pada laptop.

Pada gambar nampak data hasil eksperimen pergeseran tanah tiap sudut kemiringan. Grafik ini menunjukkan bahwa besarnya sudut kemiringan berpengaruh terhadap besarnya pergeseran tanah. Pada sudut $40^{\circ}$ dan $45^{\circ}$ terlihat terjadinya pergeseran tanah pada waktu sekitar 1.800 sekon atau 30 menit setelah dimulai penyiraman. Sedangkan pada sudut $50^{\circ}$ terjadinya pergeseran tanah yaitu pada selang waktu 2.000 sekon. Pada awalnya pergeseran tanah pada sudut $45^{\circ}$ yang paling besar, namun seiring dengan waktu penyiraman terlihat sudut $50^{\circ}$ memiliki pergeseran yang paling besar, hal ini dipengaruhi oleh gaya yang bekerja pada sistem ini, dimana semakin besar sudut kemiringanya maka semakin besar pula gaya tarik dari tanah yang menyebabkan pergeseran terjadi (Jefriyanto, 2020)

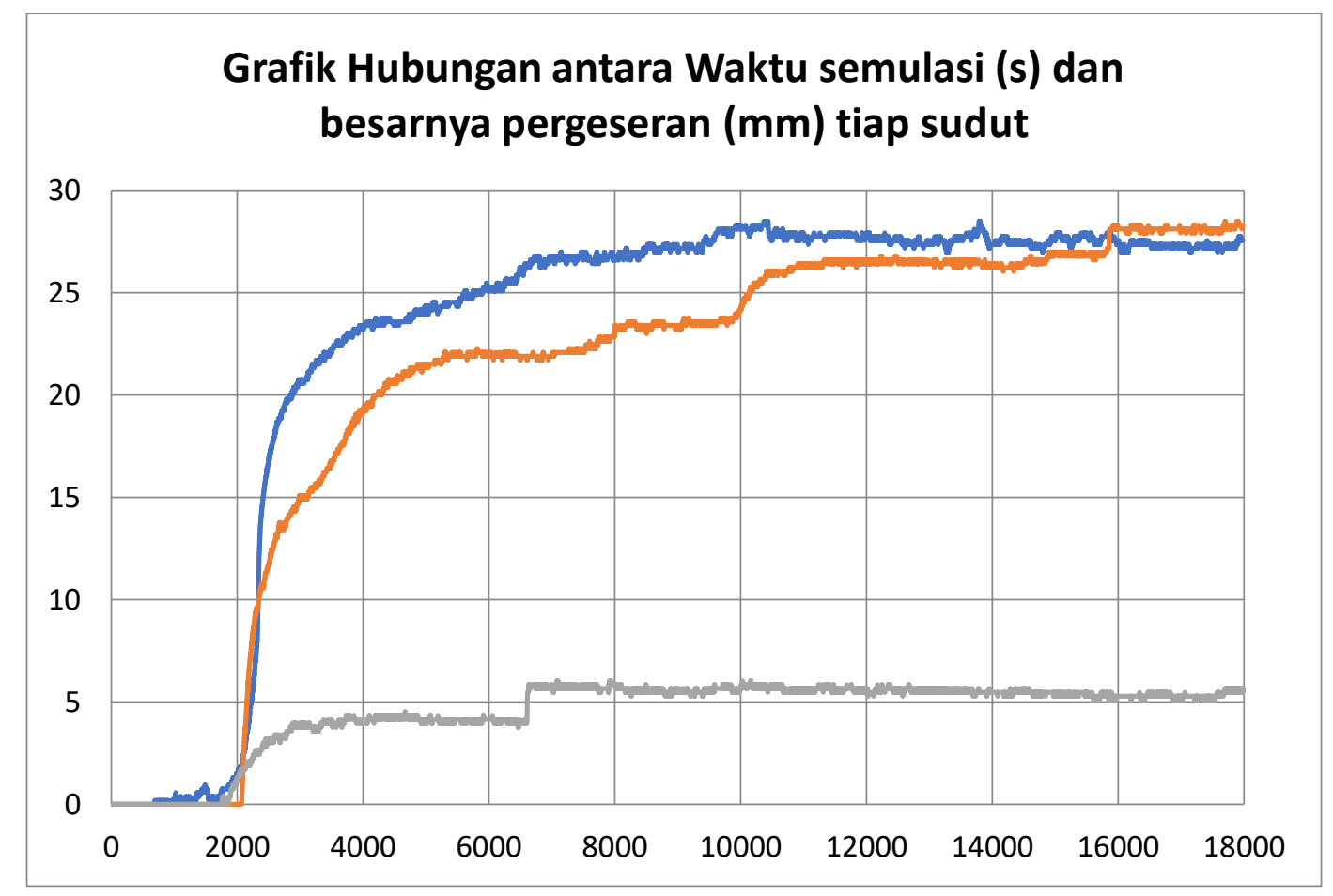

Gambar 7. Data pergeseran tanah tiap sudut

Pada waktu lama penyiraman 18.000 sekon atau 5 jam besarnya pergeseran pada sudut $40^{\circ}, 45^{\circ}$, dan $50^{0}$ yaitu $5.5 \mathrm{~mm}, 27,6 \mathrm{~mm}$ dan $28,3 \mathrm{~mm}$. Dari beberapa pengamatan terhadap peristiwa longsor yang terjadi, menurut Karnawati (2012) diperoleh suatu kesimpulan bahwa untuk suatu daerah dengan kondisi kemiringan lereng $>45^{\circ}$, apabila dalam area dengan kondisi yang labil telah terjadi pergeseran tanah sebesar $\pm 5 \mathrm{~cm}$, maka dapat dikatakan bahwa area atau wilayah tersebut berpotensi mengalami longsor (landslide). Namun dari hasil eksperimen yang dilakukan selama waktu pengambilan data saat simulasi belum terjadi landslide. Hal ini dikarenakan pergeseran tanah terjadi hanya sampai $28,3 \mathrm{~mm}$ atau sekitar $3 \mathrm{~cm}$ saja, sedangkan minimal pergeseran tanah untuk terjadinya landslide adalah $\pm 5 \mathrm{~cm}$.

\section{KESIMPULAN}

Dari hasil penelitian ini , dapat diambil kesimpulan sensor LVDT telah berhasil disimulasikan pada prototype dengan pergeseran tanah dengan ketelitian $0.01 \mathrm{~mm}$ dengan jangkauan pergeseran hingga $14 \mathrm{~cm}$. Hal ini menunjukkan sensor LVDT dapat dijadikan alat monitoring untuk pergeseran tanah yang kecil. Penelitian selanjutnya akan dikembangkan sensor LVDT dengan jangkauan pengukuran yang besar. 
https://jurnal.unsulbar.ac.id/index.php/saintifik

\section{DAFTAR PUSTAKA}

Federico, A., Popescu, M., Fidelibus, C., Interno, G. (2004) : On the prediction of the time of occurrence of a slope failure: A review. Proc. 9th Int. Symp. Landslides, vol. 2, (979-983).

Jefriyanto, W., Satria, E., dan Djamal, M. "Pengembangan Sensor LVDT (Linear Variable Differential Transformer) dengan berbagai Konfigurasi”. Seminar Kontribusi Fisika , Bandung, (2017).

Jefriyanto, W., Silka, dan Djamal, M. "Analisis Pergeseran Tanah dengan Menggunakan Sensor Kelembaban Tanah Berbasis Arduino Uno". Prosiding SNIPS 2018, FMIPA ITB, (2018).

Jefriyanto, W., Saka, B. G. M., dan Djamal, M. (2019, December 18). Desain Prototype Sensor Pergeseran Tanah dengan Menggunakan Sensor LVDT (Linear Variable Differential Transformer). Neutrino, 2(1), 25-29.

Jefriyanto, W., Saka, B., Pineng., M., Djamal, M (2020)" Development of LVDT (Linear Variable Differential Transformer) sensor as land displacement sensor". Journal of Physics: Conference Series : 1528012041

Kanchi, R. R. and Gosala, N. (2010) Design and Development of an Embedded System for Testing the Potent iometer Linearity. Sensors \& Transducers Journal, Vol. 112, Issue 1, p. 107 - 117, (2010)

Karnawati, D. (2012) : Development of Socio-Technical Approach for Landslide Mitigation and Risk Reduction Program in Indonesia. World Academy of Science: Engineering and Technology (34-53).

Kapoor, S., Pahuja, H., Singh, B.,(2016): Real Time Monitoring \& Alert System for Landslide. 2nd International Conference on Contemporary Computing and Informatics (IC3I) (584 -589).

Nuhn, E., Kropat, E., Reinhardt W., dan Pickl, S. (2012): Preparation of Complex Landslide Simulation Results with Clustering Approaches for Decision Support and Early Warning. 45th Hawaii International Conference on System Sciences (34).

Othman, A. M., (2008), Design of Economical Equipment for Water and Fuel Level Detection in Jordan. American Journal of Applied Sciences 5 (5), 2. p. 473- 478

Priyanto, J., Subagiyo, H., Madona, P., ( 2015). "Rancang Bangun Peringatan Bahaya Longsor dan Monitoring Pergeseran Tanah Menggunakan Komunikasi Berbasis GSM". Jurnal ELEMENTER. Vol. 1, No. 2, Riau

Priyanto, J., Subagiyo, H., Madona, P., ( 2015). "Sistem Instrumentasi dan Monitoring Pergeseran Tanah Menggunakan Sensor LVDT Berbasis Mikrokontroler. Proceeding of 3rd Applied Business and Engineering Conference (ABEC), pp. 810-816, Batam, 16-17 September 2015

Scaioni, M, Lu, P., Feng, T., Chen, W., Qiao, G., Wu, H., Tong, X., Wang, W., Li, R. "Analysis of spatial sensor network observations during landslide simulation experiments", European Journal of Environmental and Civil Engineering, vol. 17, pp. 802, 2013.

Vudhivanich, and Sriwongsa, W., Development of a Canal AutomationModel: A Laboratory Experiment. Kasetsart J. (Nat. Sci.) $45: 353-365$ (2011) 